MATEC Web of Conferences 13, 02014 (2014)

DOI: $10.1051 /$ matecconf/ 20141302014

(C) Owned by the authors, published by EDP Sciences, 2014

\title{
Investigation and Measurement of Copper Nanofluid Impact on Thermal Efficiency of Solar Collectors
}

\author{
Morteza Khalaji Assadi ${ }^{1}$, Yahya Nasersharifi ${ }^{2, a}$ \\ ${ }^{1}$ Associate Professor, Mechanical Engineering Department,Universiti Teknologi PETRONAS, \\ Malaysia \\ ${ }^{2}$ M.Sc. Student Islamic Azad University of Iran, Science and Research Branch, Faculty of \\ Environment \& Energy, Energy Engineering Department, Tehran, Iran
}

\begin{abstract}
This study compared the impacts of using copper nanofliud to enhance the efficiency of flat solar collectors with closed loop and under forced convection heat transfer circumstances to traditional work fluids. Various concentrations of nanoparticles in water and water/glycol, from $250 \mathrm{ppm}$ to $3000 \mathrm{ppm}$, were examined for volume fraction impact. Results indicate that the laboratory tests were different from those under real conditions because of the high concentration of nanoparticles used in laboratory tests; however, by using nanofluid (even with low concentrations around $0.3 \%$ ) solar collector efficiency improved (3.2\%). Results have also shown that the use of copper nanofluid in ethylene glycol as the base fluid causes a significant reduction in collector efficiency, due to the increase in viscosity. However, using higher flow rates caused the heat transfer rate to rise because of increased turbulence.
\end{abstract}

\section{Introduction}

A considerable number of investigations into the effects of nanofluids in heat transfer have been done in laboratories and the positive impact of these types of fluids on the heat transfer phenomena is proved. Similar investigations also have been done to report the experimental results and the potential performance of using nanofluids in solar thermal collectors. Natarajan used multiwall stabilized carbon nanotubes (CNT) in water to evaluate the changes in thermal conductivity in relation with the base fluid (water). He concluded that nanofluid has a higher coefficient of thermal conductivity than water, and if this nanofluid is used in a solar collector, efficiency will increase [1]. Tyagi investigated the efficiency of a direct absorption solar collector containing nanofluids under numerical comparison with a conventional flat plate collector. He used aluminum nanoparticles, and in this collector model, he showed that performance under normal operations was almost $10 \%$ more than performance of the conventional flat plate collector under similar conditions [2]. Otanicar carried out an experimental study on the effects of using nanofluids in a microsized direct absorption collector and showed that it had a positive effect of about $5 \%$ on collector efficiency [3]. Furthermore, he used his research results for an economic evaluation of using nanofluid in solar collectors in 2009. According to his results [3],

a Corresponding author: ynsharifi@gmail.com

This is an Open Access article distributed under the terms of the Creative Commons Attribution License 2.0, which permits unrestricted use, distribution, and reproduction in any medium, provided the original work is properly cited. 
a collector containing nanofluid had higher thermal efficiency and required less auxiliary energy, which led to the production of less greenhouse gases [4].

The purpose of this paper is to use copper nanofluids as the working fluid in the solar system and examine the effect of nanofluids on the efficiency of the solar collector in real working conditions. For this, a solar water heater system with flat solar collector was designed and installed with a forced convection loop. The nanofluids produced of copper nanoparticles with water as the base fluid and were tested in a solar collector according to the European Standards methods (EN12975). The main advantage of using copper nanoparticles in this study was that most of the tubes used in the manufacture of solar collectors are cupreous; therefore, nanoparticles could settle in molecular spaces at the wall of the tubes and produce cupreous nanofins [5]. These nanofins have a great effect on heat transfer by reducing the boundary layer effect. Moreover, according to some studies in natural convection heat transfer, there are no exact results for the positive role of nanoparticles in this case. Wen and colleagues' experiments showed that, with a rise in nanoparticles, the natural heat transfer coefficient decreased [6].Thus, based on certain experiment results regarding the positive effect of nanoparticles on forced convection [7,8], this method of heat transfer was applied for tests in the current study.

\section{Theoretical and experimental models}

One conventional laboratory method used to study the theory of nanofluids and to compare experimental results is the transient hot wire experimental method. It is a well known method generally used to measure the thermal conductivity of nanofluids [1]. But because of the lack of adequate laboratory facilities and sufficiently accurate equipment, the method used in these experiments to measure efficiency was the method proposed by EN12975. Therefore, outdoor experiments have been conducted on the actual conditions of solar radiation. In this regard, laboratory apparatus was designed and constructed in accordance with the schematic in Fig (1). The flat plate solar collector used in assembling the system had a $45^{\circ}$ angle relative to the horizon. All input and output data for the collector fluid temperatures, air temperature, and solar radiation levels were obtained, averaged, and then were applied in equations number (1) to number (3). By using these points in a graph based on $\mathrm{T}^{*}$ and across the line between the points the collector efficiency diagram could be obtained. The vertical axis represents the thermal efficiency of the collector [9].

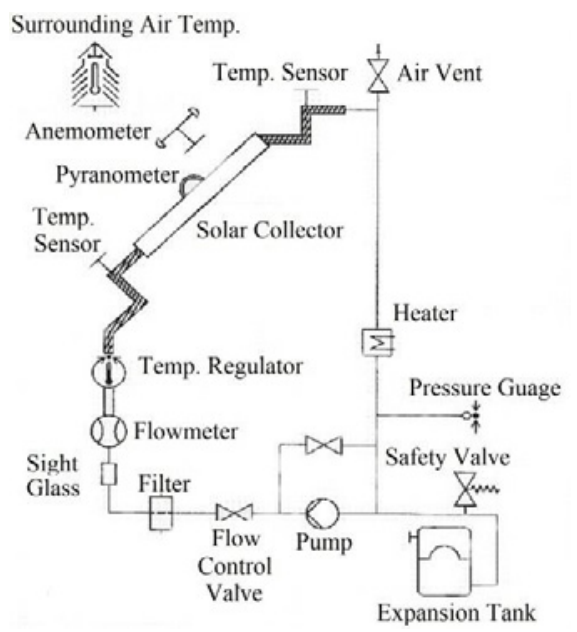

Figure. 1- Designed system (based on EN12975) [9]. 


$$
\begin{gathered}
T_{\mathrm{m}}=T_{i}+\frac{\left(T_{o}-T_{i}\right)}{2} \\
T_{m}^{*}=\frac{T_{m}-T_{a}}{G_{T}} \\
\eta_{i}=\eta_{0}-a_{1} T_{m}^{*}-a_{2} G_{T}\left(T_{m}^{*}\right)^{2}
\end{gathered}
$$

Table1- Parameters Index

\begin{tabular}{|c|c|}
\hline$T_{i}$ & collector Inlet temperature, $\left[{ }^{\circ} \mathrm{K}\right]$ \\
\hline$T_{O}$ & collector outlet temperature, $\left[{ }^{\circ} \mathrm{K}\right]$ \\
\hline$T_{a}$ & ambient temperature, $\left[{ }^{\circ} \mathrm{K}\right]$ \\
\hline$T^{*}{ }_{m}$ & reduced temperature difference $\left[\mathrm{m}^{2} \mathrm{KW}^{-1}\right]$ \\
\hline$G_{T}$ & solar irradiance, $\left[\mathrm{Wm}^{-2}\right]$ \\
\hline $\mathrm{a}_{1}$ & algebraic constants, reference to $\mathrm{T}_{\mathrm{m}}{ }^{*},\left[\mathrm{Wm}^{-2} \mathrm{k}^{-1}\right]$ \\
\hline $\mathrm{a}_{2}$ & algebraic constants, reference to $\mathrm{T}_{\mathrm{m}}{ }^{*},\left[\mathrm{Wm}^{-2} \mathrm{k}^{-2}\right]$ \\
\hline$\eta_{0}$ & zero-loss collector efficiency \\
\hline$\eta_{i}$ & collector efficiency with reference to $\mathrm{T}_{\mathrm{m}}{ }^{*}$ \\
\hline
\end{tabular}

\section{Results and discussions}

The $\mathrm{Cu}$ nanofluids were produced by Chemical Vapor Deposition (CVD) and two-step method with particles in $7 \mathrm{~nm}$ size [10] and were injected into the closed loop system. Also, to simulate real conditions and actual function, tests were carried out on a mixture of water and glycol, since actual conditions of the solar collector's operation usually comprise between $30 \%$ and $40 \%$ antifreeze as the heat transfer fluid. In order to test the effect of different nanofluid volume fractions on efficiency, nanofluids from a very low level of about $250 \mathrm{ppm}$ to $3000 \mathrm{ppm}$ were prepared separately to inject at any stage of testing. Because of the prevailing assumption in the use of copper nanofluids in copper made tubes (settling nanoparticles in holes in the tube walls and making nanofins), after loading the nanofluid, a 24 hours retention time was considered. It was observed that as concentrations of nanoparticles increased, performance improved (Fig.2, Fig 3). 
MATEC Web of Conferences

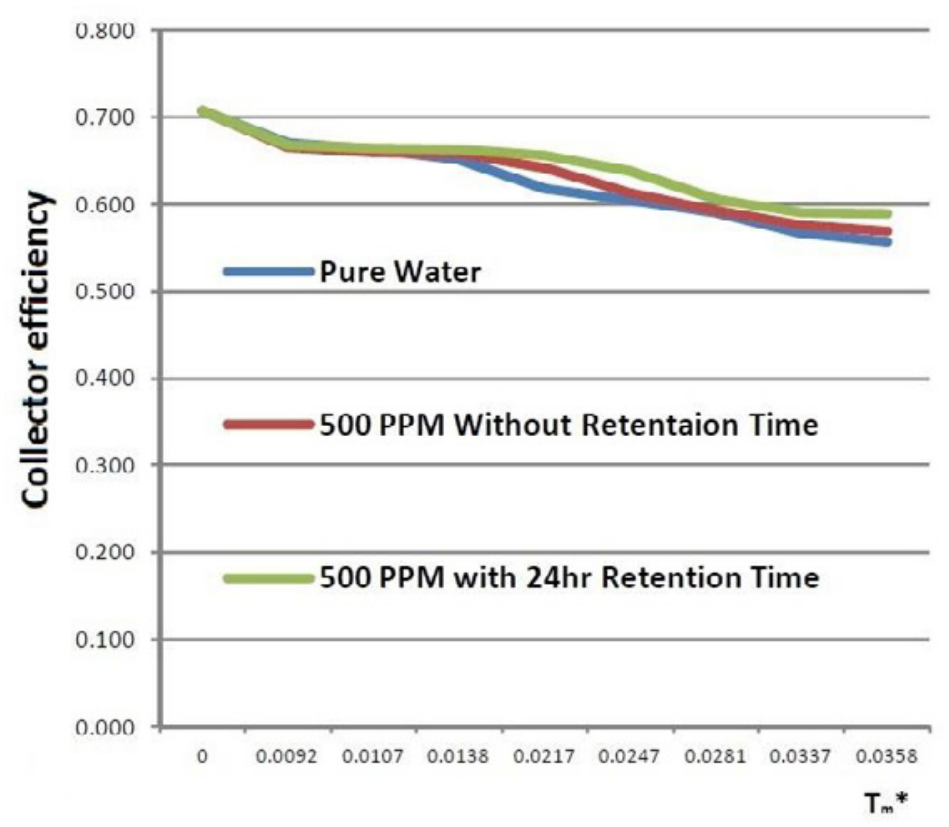

Figure.2- Collector efficiency enhancement using 500PPM nanofluids and retention time effect on nanofins formation

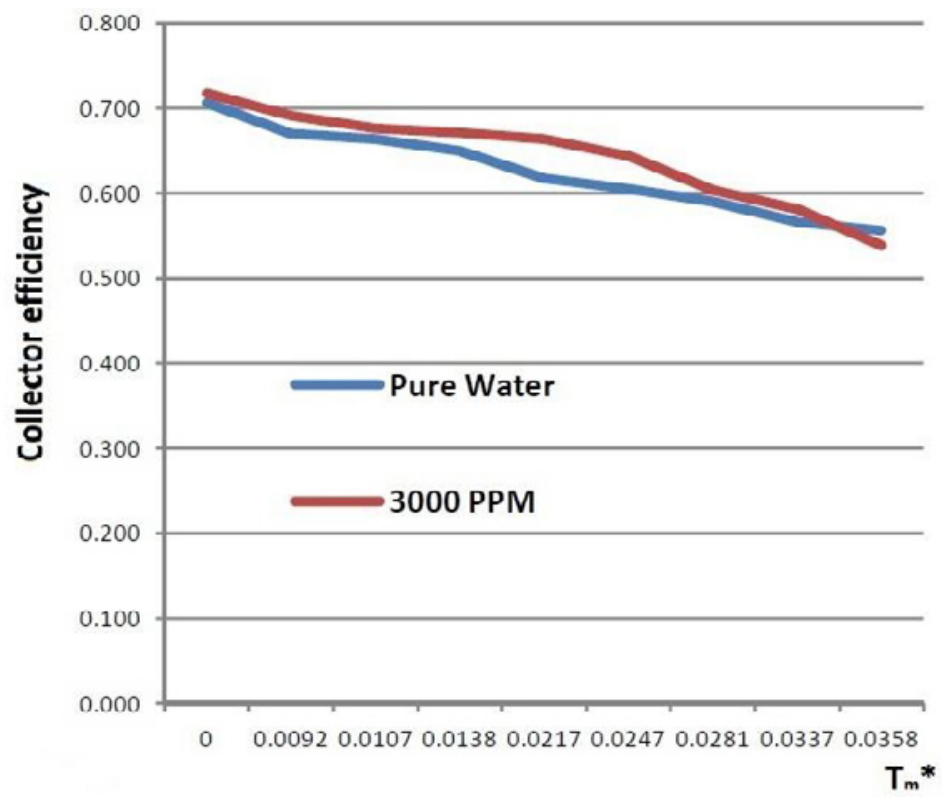

Figure.3 - Effect of 3000PPM nanofluids on collector efficiency in comparison with pure water

Other experiments during this study used nanofluids in various flow rates and also used ethylene glycol as base fluid. As can be seen in Fig. 4, when the flow rate of 2 liters per minute increased to 4 liters per minute, efficiency increased as well (the jumps in collector efficiency). Because of this fact that with an increasing Reynolds number turbulence rose. Comparing the effect of these parameters on the calculated values for base fluid (water) showed that these effects increased as flow rate rose. These 
results confirmed the results of other experiments related to the effects of Reynolds on the heat transfer of nanofluids [11, 12].Due to the higher viscosity of ethylene glycol fluid, collector efficiency at fixed flow rates with this as the base fluid fell sharply.

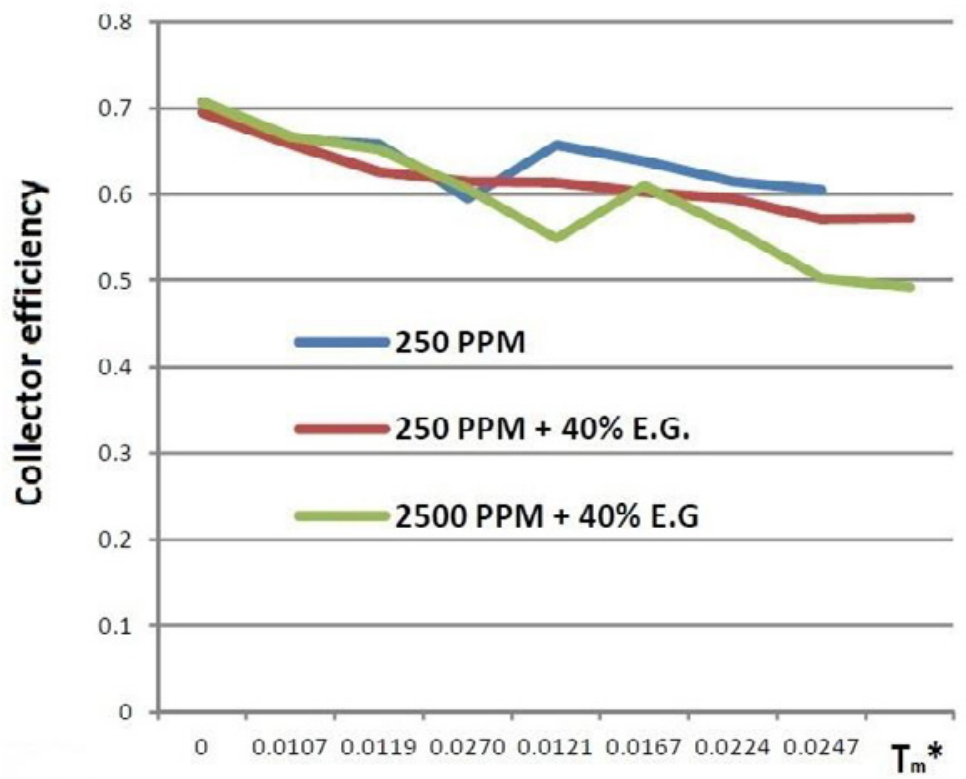

Figure.4 - Effect of flow rate on collector efficiency, a comparison between pure water, 250PPM \& 2500PPM nanofluids with water and ethylene glycol (E.G)

Analyses of the effects of varying concentrations of copper nanofluids in the solar collector are shown in Table 2. Fluctuations existed in data, but the overall trend is indicative of increasing efficiency with rising particle numbers. Despite using a different method for measuring the effects of nanoparticles on heat transfer, results of this study are highly similar to results of other studies with different nanoparticles [13]. Natarjan's results in low concentrations of CNT particles show an increase of around $3 \%$ to $5 \%$ in collector thermal efficiency, which certifies the results of our studies [1].

Table2-Maximum increase in solar collector efficiency using varying volume fractions of nanoparticles in comparison with pure water

\begin{tabular}{|c|c|c|c|c|c|c|c|}
\hline Concentration [PPM] & 250 & 500 & 1000 & 1500 & 2000 & 2500 & 3000 \\
\hline Max Increase in Eff. [\%] & 3 & 2.5 & 1 & 2.5 & 3 & 2.1 & 3.2 \\
\hline
\end{tabular}

\section{Summary}

Experiments showed that by increase in concentration, the nanoparticles effects were more significant. Higher flow rates are allowed for increased heat transfer rates for both water and ethylene glycol as the base fluid because of the increased turbulence. Another notable consideration for $\mathrm{Cu}$ nanofluid in the collector was the effect of a 24-hour retention time. This indicated that the improved effect of the nanofins on tube walls was greater with the retention time. It also indicated that the formation of nanofins on the tube walls reduced the effects of the boundary layer and increased the heat transfer rate. 


\section{References}

1. Natarajan, E. and Sathish, R., Role of nanofluids in solar water heater. Int J Adv Manuf Technol,(2009).

2. Tyagi, H., Patrick, P., and Ravi, P., Predicted efficiency of a low-temperature nanofluid based direct absorption solar collector. Journal of Solar Energy Engineering, Vol.131 / 041004 (2009).

3. Otanicar, T., Phelan, P. E., Rosengarten, G., and Prasher, R. S., Experimental testing and modeling of a micro solar thermal collector with direct absorption nanofluids. In Proceedings of the Inaugural US-EU China Thermophysics Conference; Beijing, China (2009).

4. Otanicar, T., and Golden, J., Comparative environmental and economic analysis of conventional and nanofluid solar hot water technologies, Environ. Sci. Technol, 43, pp. 6082-6087,( 2009)

5. Zhou DW. Heat transfer enhancement of copper nanofluid with acoustic cavitation. Int $\mathbf{J}$ Heat Mass Transfer (2004).

6. Dongsheng Wen, Yulong Ding., Formulation of nanofluids for natural convective heat transfer applications International Journal of Heat and Fluid Flow, (2005).

7. Li Q, Xuan Y. Convective heat transfer and flow characteristics of $\mathrm{Cu}$-water nanofluid. Sci China (Ser E),(2002).

8. Wen D, Ding Y. Experimental investigation into convective heat transfer of nanofluids at the entrance region under laminar flow conditions. Int J Heat Mass Transfer (2004).

9. BS EN 12975 Standard, Technical Committee, RHED/25, BSI, ISBN 0580367487, (2000).

10. Wang, H., Dispersing carbon nanotubes using surfactants, Current Opinion in Colloid \& Interface Science 14 ,pp. 364-371, (2009).

11. Lai, W. Y., Vind, S., Phelan, P. E., and Prasher, R., Convective heat transfer for water-based alumia nanofluids in a single 1.02-mm tube, J. Heat Transfer, 131,11,pp. 112401, (2009).

12. Anoop, K.B., Effect of particle size on the convective heat transfer in nanofluid in the developing region. 9-10, pp. 2189-2195, (2009).

13. Masuda, H., Ebata, A., Teramae, K., Hishinuma, N., Alteration of thermal conductivity and viscosity of liquid by dispersing ultra-fine particles (dispersion of g-Al2O3, $\mathrm{SiO} 2$ and $\mathrm{TiO} 2$ ultra-fine particles). Netsu Bussei (Japan), 4(4), (1993). 